\title{
THE PROSPECT OF KNOWLEDGE GROWING SYSTEM (KGS) FOR PLANT DISEASE EARLY DETECTION SYSTEM
}

\author{
Ika Noer Syamsiana*
}
Department of Electrical Engineering, Politeknik Negeri Malang, Malang, Indonesia
*Corresponding author
Email: ikanoersyamsiana@polinema.ac.id

Pests and diseases significantly contribute to crop production losses. The primary diseases found are fungi, bacteria, and viruses. These diseases affect the growth and development of the plant and lead to harvest loss or failure. The microscopic test is one of the conventional technology that is still used for detecting plant disease. This test is very accurate in delivering the results but the test process is very expensive.

Pattern recognition combined with image processing offers a low-cost approach to identify plant disease and many research articles proposed Machine Learning and Deep Learning to deliver very high accuracy in determining and classifying healthy plants. However, most of the methods need a huge dataset and require significant time to make the annotations.

Knowledge Growing System (KGS), one of the methods in Cognitive Artificial Intelligence (CAI). KGS uses a different approach from Machine Learning and Deep Learning, It does not learn from the prepared annotated data but it learns directly from the phenomenon or object and grows its own knowledge during interactions.

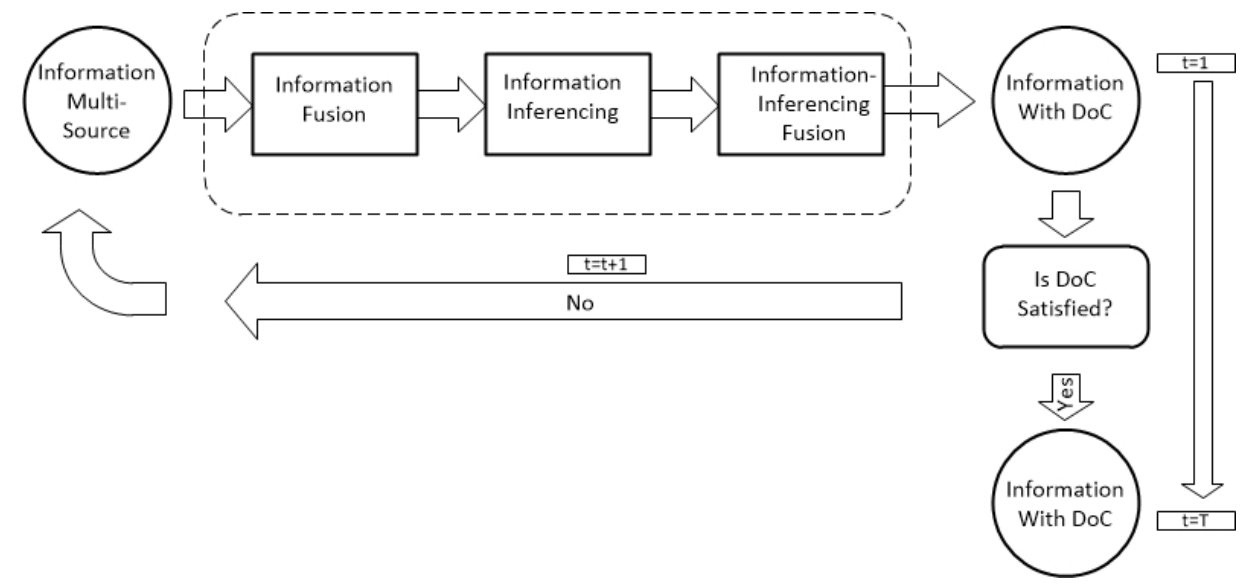

Figure 1. The model of KGS mechanism in obtaining new knowledge.

Basically, KGS is a system that is able to grow its own knowledge as the accretion of information as the time elapsed. This concept derived from the observation of the mechanism that 
occurs within human brain when performing information inferencing fusion to generate new knowledge. KGS is developed by referring to Human Inference System (HIS). The process in obtaining new knowledge is carried out in three simple steps after receiving data or information regarding the phenomenon or object being observed, namely information fusion, information inferencing, and information inferencing fusion as depicted in Figure 1. New knowledge is obtained by applying a mechanism called as Degree of Certainty (DoC), which means the value that determines the knowledge obtained by KGS after making interactions with the phenomenon or object.

KGS has already been applied in various fields such as bioinformatics, decision making, cybersecurity, health, early warning system, Covid-19 detection system. and others including cognitive processor. KGS is CAI technology invented by two Indonesian researchers, namely Colonel Assist. Prof. Dr. Ir. Arwin Datumaya Wahyudi Sumari, S.T., M.T., IPM, ASEAN Eng., ACPE and Prof. Dr. Ir. Adang Suwandi Ahmad, DEA, IPU. It is an original product of Indonesia and has already gotten registered patent number P00201902101 dated March 12, 2019. In the near future, KGS is very prospective to be applied as a plant disease early detection system.

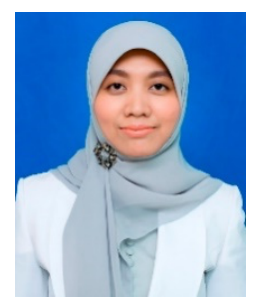

Ika Noer Syamsiana, ST, MT Member of Editorial Board 